\title{
Cognitive Workload as a Predictor of Student Pilot Performance
}

\author{
Nathan F. Tilton ${ }^{1}$ and Ronald Mellado Miller $^{2}$ \\ ${ }^{1}$ Embry-Riddle Aeronautical University, Worldwide Campus, \\ PO Box 31252, Honolulu, HI 96820, USA \\ ${ }^{2}$ Brigham Young University-Hawaii, 55-220 Kulanui St. \#1896, \\ Laie, HI 96762, USA \\ dnates@gmail.com, ronald.miller@byuh.edu
}

\begin{abstract}
This study examined the relationship between cognitive task load and performance in pilot training in a civilian pilot training program. It was found that the NASA task load index was indicative of training success, with the most successful pilot trainees showing the most cognitive task load and vice versa for those performing poorly. The implications for this finding are discussed as is their relation to possible advantages to military pilot trainees over their civilian counterparts.
\end{abstract}

Keywords: task load, cognition, TLX, aviation, training, civilian, military.

\section{Introduction}

Flight researchers define "mental' (or cognitive) workload as, "the mental cost placed on the pilot by performing the necessary mental processing to accomplish the mission" (Vidulich, 2003, p. 117). Maintaining control of the aircraft places large workload demands on any pilot. Unfortunately, cognitive tunneling can occur when a pilot focuses on primary flight tasks to exclude all other task requirements (Vidulich, 2003).

Today, flight training is taking place in more Technologically Advanced Aircrafts (TAA) (Craig, Bertrand, Dornan, Gossett, \& Thorsby, 2005). Glass cockpits integrate the standard instruments, avionics, and GPS. The result is that the majority of instruments in a normal cockpit are reduced to a 10-inch Primary Flight Display. TAA's also include a Multi-function Display that displays the engine and navigational displays while serving as a backup if the Primary Flight Display (PFD) fails (Craig, Bertrand, Dornan, Gossett, \& Thorsby, 2005). Furthermore, pilots must also communicate, fly the aircraft, and follow all applicable regulations.

Students have to satisfy the requirements of the flight syllabus to advance. Part 61 and Part 141 flight programs require that the student make adequate progress. If the student fails to do so in a Part 141 program, where college credit is often granted, course failure can occur. It may be assumed that students who repeatedly perform poorly will suffer from increased stressed on subsequent trials due to the prospect of failure, even if that same stress motivates them in the short-term. 
Interestingly, the history of psychologically based evaluations for predicting pilot training performance shows that there is some confusion over their utility and predictiveness. For example, one of the earlier studies, by Jessup and Jessup (1971), indicated that, in terms of one measure (the Eysenck Personality Inventory), the most likely candidate to pass the Royal Air Force (RAF) pilot training was identifiable based on psychological criteria. They found that a "stable-introvert" was the most likely to pass while "neurotic-introverts" were the least likely. The explanation for this difference was that the "neurotic-introvert" is more easily aroused and more likely to arouse beyond the learning threshold and, thus, under-learn and underperform. However, other, more recent studies (Hedge, Bruskiewicz, Borman, Hanson, Logan, \& Siem, 2000) have found that cognitive, psychomotor, and biodata instruments have been among the best predictors of pilot performance whereas personality measures have tended to be less predictive statistically.

On the other hand, psychology and performance are clearly linked. Bor and colleagues (Bor, Field, \& Scragg, 2002) found that among those RAF pilots who have ejected from their aircraft, $40 \%$ reported prolonged psychological disturbances. These were seen as being the result of the pilots being active, self-confident, and competitive with a tendency towards perfectionism. The disturbances themselves manifested as addictive behavior, anxiety, marital conflict, somatization, depression, and phobic reactions. Even the more recent undergraduate pilot training (UPT) programs, which include perceptual and motor tests to evaluate potential pilots, utilize some psychological measures. For example, the Basic Attributes Test (BAT), a measure of potential pilot performance that the U.S. Air Force used prior to 2006, includes tests on item recognition to measure short term memory, self-crediting word knowledge to examine self-confidence, and an activities interest inventory to determine attitudes toward risk taking (Carretta, 2002). Such measures have increased the UPT success to roughly $75 \%$ of those chosen (Carretta, 2002), a high degree of success by any measure.

The main concern regarding student pilots is that sustained cognitive workloads can hamper the development and progression of the student. Some key issues to consider for effective flight training are how far does the student want to progress in their career. Patrick (2003) states that the more the training will impact their future career, the more motivated the students will be. One area that affects a student pilot's motivation in flight training is how useful that training is to them. Patrick (2003) defined four areas of training evaluation, namely: goal orientation, cost effectiveness or cost benefit of the training, a research oriented approach using variations of the scientific method, and finally, qualitative analysis of flight training, that is not dissimilar from the first method of training evaluation.

For those students in the FAA-approved collegiate flight training programs, the motivation is to complete the course in the allotted time of one college semester. If workload is high for too long, motivation for flight training will decrease as observed by a reduction in flights per week, or voluntary removal from the program. Based on individual performance, an increase in workload will occur at different times, however, in certain students who have low motivation, workload should peak at a predictable level across the board independent of lesson number. If high workload levels can be predicted, measured, and addressed, student pilots should remain in the program (Haber \& Haber, 2003). 


\section{Method}

\subsection{Participants}

Participants in this study were twenty Part 61 students enrolled at Honolulu Community College (HCC) for credit. The majority of students were in their early twenties.

\subsection{Materials}

The NASA Task Load Index was used to measure cognitive workload (Hart, 2007). The NASA TLX is a scale of 6 factors which are: Mental Demand, Temporal Demand, Physical Demand, Emotional Demand, Frustration, and Performance (Hart, 2007). The NASA TLX is considered to be highly reliable and is currently used to validate other workload scales. The NASA TLX is considered valid and has a longitudinal Cronbach Alpha greater than 0.80 (Hart, 2007).

\subsection{Procedure}

The data was collected over time after each flight and the results were recorded along with the syllabus flight number, flights per week, instructors, GPA, and course load. The data was analyzed by Statsoft Statistica 8 for trends in flight training.

Flight training was divided into three blocks. Block one prepared students for the first solo and served as the current test.

\section{Results}

Out of the 25 students in HCC's program, 3 soloed on time and only 5 completed the course. These 5 students were reported to have less pilot error by their flight instructors. In addition, those students showed higher mental, temporal, effort, and frustration characteristics as measured by the NASA TLX. The raw TLX scores are reported here as recommended by Byers, Bittner, and Hill (1989). Over 66\% of the total body of students had to repeat multiple lessons due to task saturation. These students reported being overwhelmed. One subject was unable to complete the first six lessons without severe shaking. One student dropped the program before completing block one.

\section{Discussion}

The scores on the NASA TLX ratings for mental, temporal, and performance demand showed the greatest differences between those who passed and those who did not. Marginally, those who passed had slightly higher TLX scores for effort and frustration. This result suggests that although pilot training is often thought of as being task based, emotional characteristics of the training should be taken into account in order to make training more effective. This may be much more the case in civilian pilot training, as here, because these pilots may lack the physical and emotional support 


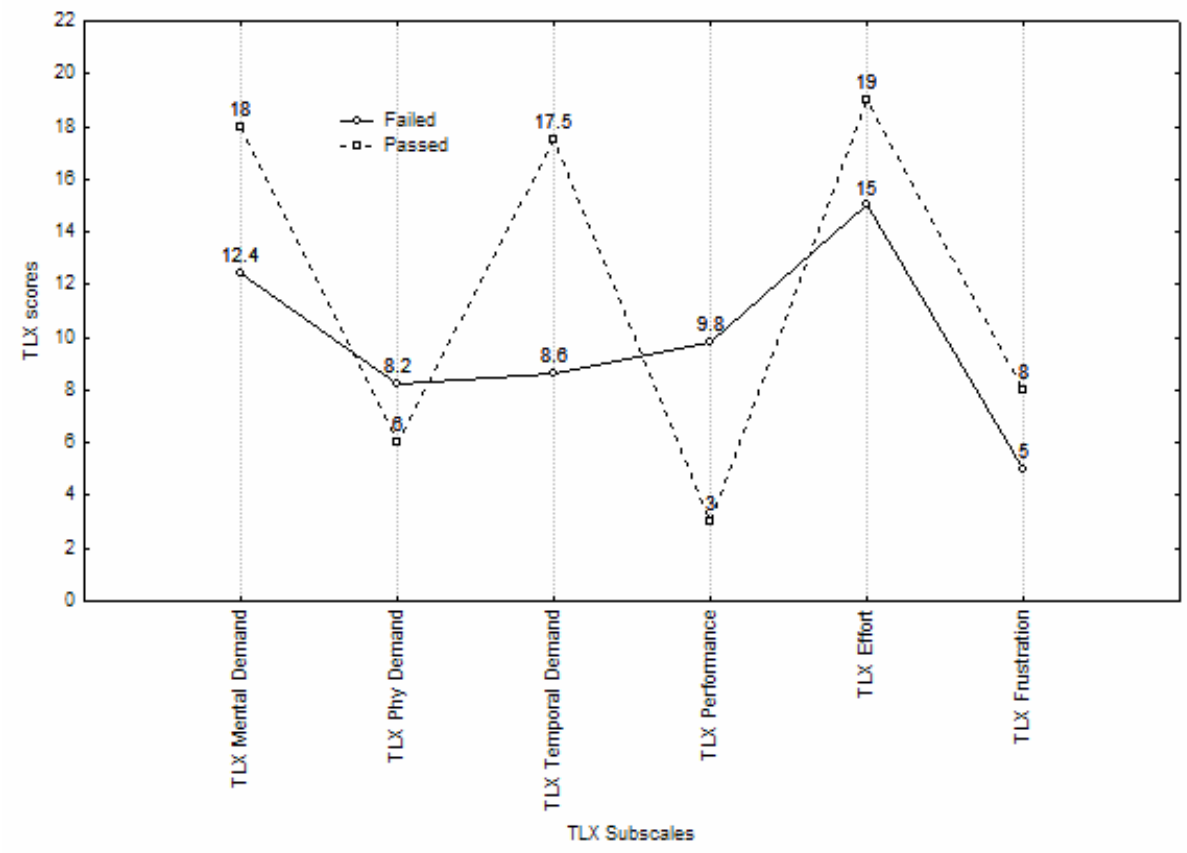

Fig. 1. This figure shows the mean TLX scores for the pilot trainees. Those who passed had higher TLX mental demand and temporal demand scores and marginally higher TLX effort and frustration scores as well as better performance scores than those that did not pass.

network military pilots share. While those who passed note the mental and temporal difficulty involved, this may have been indicative of their focus and drive, which in turn may also have led to their more positive appraisals of their performance. However, that only $12 \%$ of students soloed on time, $20 \%$ completed the course, and $2 / 3$ had to repeat portions is note worthy not only because of the high failure rate on this task but because the military success rate for the program (75\% according to Carretta, 2002 ) is so high. Without a community of support (as in the military), it appears that the civilian trainees had a harder time focusing on the tasks needed to succeed.

The kinds of support that military personnel receive are extensive. Commanders and flight mates provide mentorship and a community to support the student pilot. This sense of belonging to a community that is either going through similar training or has in the past should not be overlooked in terms of its motivational and inspirational utility for student pilots struggling to pass. Similarly, while civilian pilots may feel excited to fly, military pilots are often seen as "elite" in the sense that their aircraft are typically among the most expensive, fastest, and are used to defend their country in potential combat. Coupled with the sense of community, these could serve as powerful strengths to the military trainee's psychology.

On the other hand, the military also offers a great deal to those who do feel overwhelmed and stressed. In the Air Force, there are service-wide mental health 
organizations as well as Chaplain based services to provide for stress counseling, life skills training, and the like. Moreover, there is an understanding of the complexity of the life style for pilots. For the pilot's family, there are wives clubs and Heartlink programs which sponsor social events and give emotional support. Lastly, the military pilot is paid to train and become the best pilot, allowing a level of focus uncommon in the civilian world where a student pilot may need to work other jobs, take other classes, etc., that distract from the ability to accomplish the difficult task of pilot training. Each of these advantages for the military has a counterpart in the civilian world, but in totality, they seem to speak to a level of support and understanding that assists the military pilot to succeed in greater measure than their civilian counterparts. Further study seems warranted to determine the nature and extent of this relationship, as hypothesized. If found, perhaps modifications to current programs for civilian student pilot training could be implemented in order to correct this imbalance and allow a greater number of qualified pilots to serve their communities and nations.

\section{References}

1. Bolstad, C.A., Endsley, M.R., Howell, C.D., Costello, A.M.: General Aviation Pilot Training for Situational Awareness: An Evaluation. In: Proceedings of the 46th Annual Meeting Human Factors and Ergonomic Society, Santa Monica, CA, pp. 21-25 (2002)

2. Bor, R., Field, G., Scragg, P.: Counselling Psychology Quarterly, vol. 15, pp. 239-256 (2002)

3. Byers, J.C., Bittner, A.C., Hill, S.G.: Traditional and raw Task Load Index (TLX) correlations: Are paired comparisons necessary? In: Mital, A. (ed.) Advances in Industrial Ergonomics and Safety, vol. I, pp. 481-485. Taylor and Francis, London

4. Carretta, Thomas, R.: Understanding the relation between selection factors and pilot training eprformance: does the criterion make a difference. International Journal of Aviation Psychology 2, 95-105 (2002)

5. Craig, P.A., Bertrand, J.E., Dornan, W., Gossett, S., Thorsby, K.K.: Ab initio training in the glass cockpit era: new technolgy meets new pilots. In: Proceedings of the 13th International Symposium on Aviation Psychology, Columbus, Ohio (2005)

6. Haber, R.N., Haber, L.: Principles and practice of aviation psychology. Lawrence Erlbaum Associates, Inc., Mahwah (2003)

7. Hart, S.G.: NASA-Task Load Index (NASA TLX). In: Proceeding of the Human Factors and Ergonomic Society 50th Annual Meeting, pp. 904-908. Human Factors and Ergonomic Society, Santa Monica (2007)

8. Hedge, J.W., Bruskiewicz, K.T., Borman, W.C., Hanson, M.A., Logan, K.K., Siem, F.M.: Selecting pilots with crew resource management skills. International Journal of Aviation Psychology 10, 377-392 (2000)

9. Jeppesen. Guided Flight Discovery Private Pilot. Englewood, CO: Jeppesen (2007)

10. Jessup, G., Jessup, H.: Validity of the Eysenck Personality Inventory in Pilot Selection. In: Occupational Psychology, vol. 45, pp. 111-123 (1971)

11. Li, G., Grabowski, J.G., Baker, S.P., Rebok, G.W.: Pilot Error in Air Carrier Accidents: Does Age Matter? Aviation, Space, and Environmental Medicine 77(7), 737-741 (2006)

12. O’Hare, D.: Principles and Practices of Aviation Psychology. In: Tsang, P.S., Vidulich, M.A. (eds.). Lawrence Erlbaum Associates, Inc., Mahwah (2003) 
13. Ottati, W.L., Hickox, J.C., Richter, J.: Eye scan patterns of experienced and novice pilots during Visual Flight Rules (VFR) navigation. In: Proceedings of the Human Factors and Ergonomic Society 43rd Annual Meeting, pp. 66-70. Human Factors and Ergonomic Society, Santa Monica (1999)

14. Patrick, J.: Principles and Practices of Aviation Psychology. In: Tsang, P.S., Vidulich, M.A. (eds.), Lawrence Erlbaum Associates, Inc., Mahwah (2003)

15. U.S Department of Transportation (2008). FederalAviation Regulations| Aeronautical Information Manual. Aviation Supplies \& Academics, Inc., Newcastle (2009)

16. Vidulich, M.A.: Principlesand Practices of Aviation Psychology. In: Tsang, P.S., Vidulich, M.A. (eds.), Lawrence Erlbaum Associates, Inc., Mahwah (2003) 